\title{
Research on Lotus Pattern Logo Design on Digital Background - Taking Jiaoshan Buddhist Academy for Instance
}

\author{
Hongqi Wang ${ }^{1 *}$ \\ ${ }^{1}$ Jiangsu University Jingjiang College Zhenjiang City, Jiangsu Province
}

\begin{abstract}
Under the background of digital design and digital propagation, this article is writing to explore the application of lotus pattern in the logo design of Jiaoshan Buddhist Academy in Zhenjiang to realize the inheritance and innovation of Buddhist culture in the logo design of Buddhist Academy, and expand the cultural connotation of logo design for Buddhist Academy. By studying the characteristics and images of Buddhist lotus patterns, combined with the aesthetic and psychological needs of monks and believers, hereby to discusses the feasibility of applying lotus patterns in the logo design of Buddhist Academy.
\end{abstract}

\section{Introduction}

The party and the government has attached great importance to the cultivation of Buddhist talents, and constantly increased their support for Buddhist education. Buddhist education and monk training is the basic work related to the healthy development of Chinese Buddhism in the future. In April 2016, when General Secretary Mr. $\mathrm{Xi}$ delivered an important speech at the National Conference on religious work, he pointed out that we should adhere to the standards of being politically reliable, religious attainments, serving the public in moral character and acting at the crucial moment, and supporting the religious sector in building a qualified talents team. The General Secretary Mr. Xi's important speech pointed out the direction for the Buddhist Education in the new period and put forward fundamental requirements.

According to research, the main characteristic of Chinese Buddhism is to advocate and practice Mahayana Bodhisattva whose greatest characteristic is not the result itself, but the cause of achievement. Such kind of Mahayana Bodhisattva Taoism, which focuses on the pursuit of results and blessings in traditional Buddhism, is full of positive energy and conforms to the Iron Law (Law of cause and effect) of Buddhism. It should be said that it represents the healthy development of Chinese Buddhism in the future and conforms to the direction of Chinese socialist core values. As an educational institution for spreading Buddhist culture and cultivating Buddhist monks, Buddhist colleges should have the consciousness and self-confidence of Buddhist culture, and have a process of keeping pace with the times. In a sense, the process of keeping pace with the times is to insist on continuous innovation. We should innovate the brand of Buddhist culture and take the logo of Buddhist Academy as the carrier, so that the traditional Chinese culture, including but not restricted to Chinese Buddhism, can continuously play its cultural confidence and the value and role of traditional culture communication.

\section{The historical deputy and influence of Jiaoshan Buddhist College}

Dinghui temple in Jiaoshan mountain, known as Puji temple in ancient times, was built in the first year of Xingping in the Eastern Han Dynasty. It is a famous ancient Buddhist Taoist temple in China and one of the earliest Buddhist temples in the south of the Yangtze River. Chuan Deng Lu, an ancient document that records the origin and development of Buddhism in China, is called the ancestral hall of all dynasties. It has the tradition of "Jiao Xia" (that is, the location for learning and practicing the doctrines of various sects and promoting the Buddhist Culture). Fabao $\mathrm{Ji}$ who is the student of master Xuanzang in Tang Dynasty, came to Jiaoshan mountain to build the grand hall. It was renamed Puji temple in Song Dynasty and Jiaoshan temple in Yuan Dynasty. It was destroyed by fire. During the reign of Xuande in the Ming Dynasty, monk Juechu rebuilt the temple with the architectural style of the Ming Dynasty. When Emperor Kangxi of the Qing Dynasty came to visit Jiaoshan mountain, he personally wrote the name of the temple plaque, and then changed the name of the temple to Dinghui temple, which is still in use today.

In 1934, master Zhiguang, abbot of Dinghui temple, founded Jiaoshan Buddhist Academy in response to Master Taixu's proposal to develop life Buddhism. From its establishment in 1934 to its suspension in 1948, nearly 300 monks were trained. At that time, Jiaoshan Buddhist Academy in China was one of the most famous and the longest lasting Buddhist College in China, known as Tsinghua University and Peking University in Buddhist.

\footnotetext{
*Corresponding author: 361090157@qq.com*
} 
Many of the monks trained by the academy became the backbone and famous monks in Chinese Buddhist in the second half of the 20th century. After graduation, most of them served as supervisors and abbots of temples. After 70 years, Jiaoshan Buddhist Academy opened again in 2018. Therefore, Jiaoshan Buddhist academy is also known as the landmark achievement of Chinese Buddhist innovation movement in the 20th century. Master Xingyun, a well-known master in mainland China and Taiwan, studied in Jiaoshan Buddhist Academy in 1945, and his legal name is Jindu. He said that Buddhism in the world looks at China, Chinese Buddhism looks at Jiangsu, and Jiangsu Buddhism looks at Zhenjiang. He sighs that without Jiaoshan, there will be no my nebula, and my parents have given birth to me, but Jiaoshan has given me wisdom.

\section{The meaning of lotus pattern in Buddhism}

In Buddhism, lotus is not only a realistic lotus, but a symbol with religious spirit whih has highlighted the sanctity of Buddhism and become a religious symbol bearing the abstract meaning of Buddhism. Lotus image has rich connotation in Buddhism, which represents the holiness of Buddha, the beauty of Buddha Kingdom, the purity of Buddha nature and the dexterity of Buddhism. Lotus is the manifestation of Buddha, the messenger of pure land world, and the symbol of Buddhism. Sakyamuni founded Buddhism, carried out caste equality, took compassion as his heart, and advocated the abolition of the strict hierarchy system. In order to spread Buddhism and make the people understand and accept the Buddhist doctrine, they preached in common sayings. It is aligned with the people's psychology of loving lotus, which makes Buddhism spread rapidly and has many believers. Therefore, lotus is frequently used as the metaphor in Buddhist scriptures. Lotus not be dirty even it lives in mud, which symbolizes the transformation from worry to purity, so it is the embodiment of Saint born in the pure land of Buddha. Therefore, lotus pattern elements are not only used in the design of Buddhist cultural symbols, but also widely used in other fields. Let the public (believers) naturally produce visual and auditory association in watching and give people the aesthetic feeling of the beauty of form is pleasing to the eyes, and the beauty of meaning is to feel the heart.

\section{Strategy of logo design of Buddhist Academy}

The logo of Buddhist Academy is the basic core element and symbol to convey the brand image of Buddhist Academy. The logo design of Buddhist Academy needs to be combined with the needs of running a school in the new era and keep pace with the times. Since the eighteen Party's Congress, General Secretary Mr. Xi has pointed out many times that cultural self-confidence and cultural self-confidence are the Chinese people's affirmation of their own traditional culture. In the new era, traditional
Buddhist culture will be displayed to the public (believers) in the form of visual symbols. Applying Buddhist culture to logo design based on Chinese traditional Buddhist culture, combining Buddhist art culture and innovation in Buddhist culture into the symbol carrier, innovatively designs brand visual symbols with its own Buddhist culture characteristics of Jiaoshan Buddhist Academy.

This combination of traditional Buddhist culture and modern culture is not only easier for the public (believers) to accept, but also can further stimulate the patriotic enthusiasm of young people in the new era and enhance cultural confidence.

\section{The innovation of Buddhist Academy logo}

\subsection{Graphic elements}

The flower bud, petals, monk (sitting Buddha) form and Buddhist scriptures of lotus pattern are integrated into one. The Buddhist monk (sitting Buddha) is skillfully combined with the open lotus shape by reading the Buddhist scriptures with one hand. The main body is the lotus pattern, forming that there is Buddha in the lotus and the Buddha is sitting in the lotus. The lotus seat in full bloom is also like a opened Buddhist sutra. The exquisite design concept of inclusiveness and openness is formed through the virtual and real situation between the figures, forming the implication that there is Buddha in my heart, representing the great perfection of one mind, two truths, eight learning and nine grades of lotus terrace, highlighting the distinct Buddhist thought and spirit (as shown in figure 1).

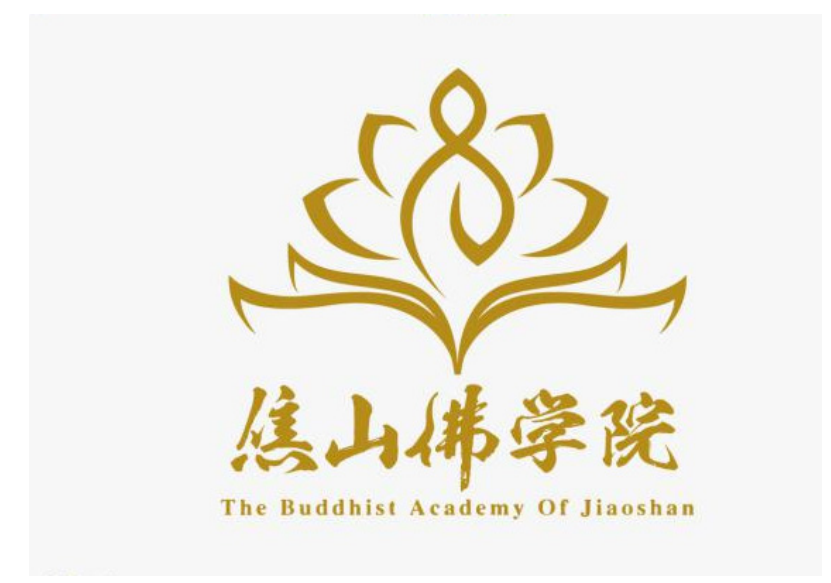

Figure 1 The logo of the Buddhist Academy of Jiaosahn

\subsection{Design}

The lotus is designed as an open form, implying the ambition of the monk to be vigorous, prosperous and be insist on the Buddha's wisdom. At the same time, the shape contains the form of left hand meditation and right hand Buddhist cultivation, and the left hand meditation also has the implication of controlling the mind. The shape of the lotus shaped Scripture points to the word Buddha in Jiaoshan Buddhist Academy below represents 
One Heart to Buddha, which means that the selfconsciousness of the Buddhist monk (believer) is the foundation of Buddhism. The lotus petals on the left and right of the Sutra symbolize Two Truths, which means that the true and the common can be integrated into one's mind. The lotus pattern is divided into eight parts on both sides, implying that the new era Buddhist Academy adheres to the Eight Learning of Harmony to study and cultivate the doctrines of each sect and to promote the Buddhist culture, implying a new Buddhist thought of tolerance and openness. The lotus shape is nine petals, symbolizing Jiupin Lotus Terrace. It is implied by the Pure Land Sect of Buddhism that after death, the person with perfect practice can go to the Western Paradise and sit on the lotus pedestal. Because of the different levels of practice before their lives, there are nine levels of different lotus platforms, and the Jiupin lotus terrace is the highest.

\subsection{Standard font}

Jiaoshan Buddhist Academy adopts calligraphy written by master Mingshan, the abbot of Dinghui temple in Jiaoshan mountain. Master Mingshan once served as vice president of China Buddhist Association, President of Jiangsu Buddhist Association and President of Zhenjiang Buddhist Association. He is also a famous contemporary calligrapher. His calligraphy is well-known in Wei stele, which is dedicated to hide the brushstrokes. His structure is strict, and his strength is restrained. He is full of momentum and enjoys the reputation of Calligrapher Poet Master. Master Mingshan, known as one of the Four Masters actively prepared for the rebuilt of Jiaoshan Buddhist Academy. Master Mingshan is a positive admirer, inheritor and promoter of Human Buddhism advocated by Master Taixu. Taking master Mingshan's calligraphy as the standard font of Jiaoshan Buddhist Academy has more symbolic significance of carrying forward Human Buddhism culture in the new era. With the great spirit of patriotism and love of teaching in his whole life, Mingshan highlights the meaning of cohesion.

\section{Brand visual design for Buddhist Style}

The design of office supplies is highlighted in the design of brand visual application system of Buddhist Academy. Office supplies are mainly composed of file bags made of recycled paper, tags, Notepad, post it notes, business cards, envelopes, letter paper, log signature pen, log ruler, wax seal, fire paint seal, environmental protection cloth bag, etc. It is simple, it is combined and applied with lotus pattern logo for the design of office supplies, with strong visual recognition and full of Buddhist Style (as shown in figure 2 and 3 )

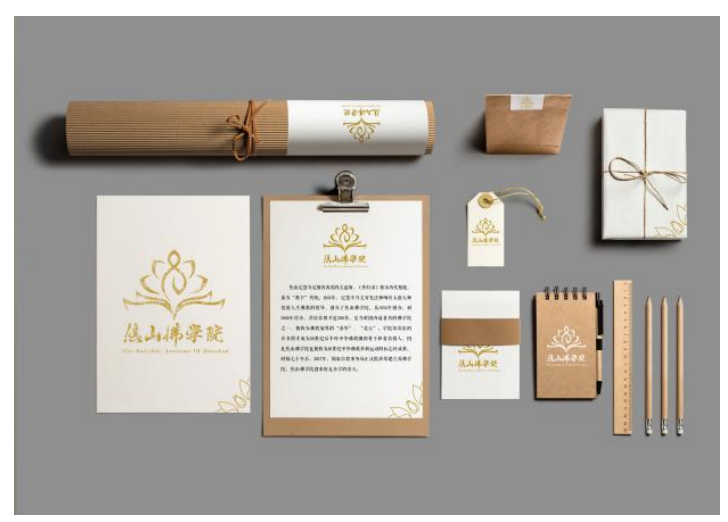

Figure 2 Office Supplier Design for Jiaoshan Buddhist Academy

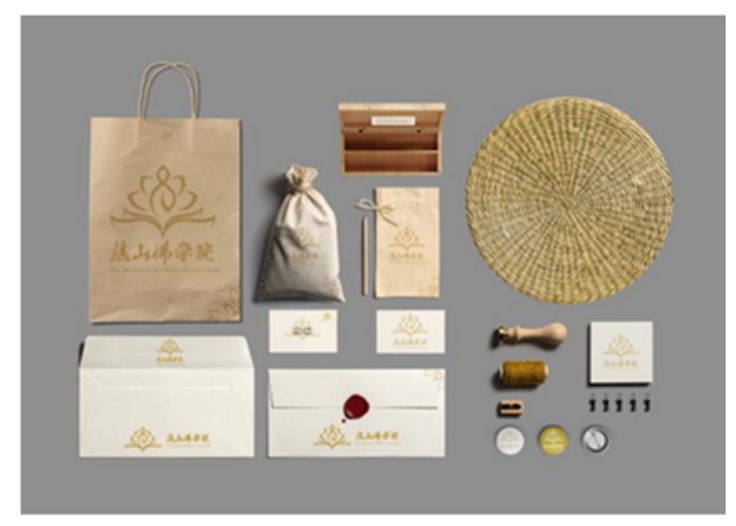

Figure 3 Office Supplier Design for Jiaoshan Buddhist Academy

\section{Creativity of cultural and creative products for Buddhist Style}

The design of cultural and creative products in Buddhist Academy would have the functions of identification, psychology and aesthetics. In addition to common cultural and creative products, such as mobile phone case, cultural shirt, postcard, backpack, key chain and so on, we should combine Buddhist cultural elements with modern design techniques. Innovative cultural and creative products design is to break through the tradition, creative cultural and creative products are mainly in the elements of refining, modeling forms and material technology innovation, so as to make it different from the common cultural and creative products. The Buddhist Academy can continue to develop fashion clothing, such as household fashion series named with One Step with One Lotus (which means walk in beauty in Chinese), Buddhist Style traveling equipment series, such as travel suits, umbrellas, backpacks, teapots, cultural goods series, such as Book and Buddhist Style integrated four treasures of the study, Buddhist art treasures, eight auspicious Xiang series which means wish everything goes well. Relying on the carrier of cultural and creative products of Buddhist Academy, the eight auspicious symbols are reconstructed and redesigned. The purple gold and eight auspicious handmade gifts by Buddhist Academy (as shown in figure 4) can be used as hand-made literary games or necklace. 


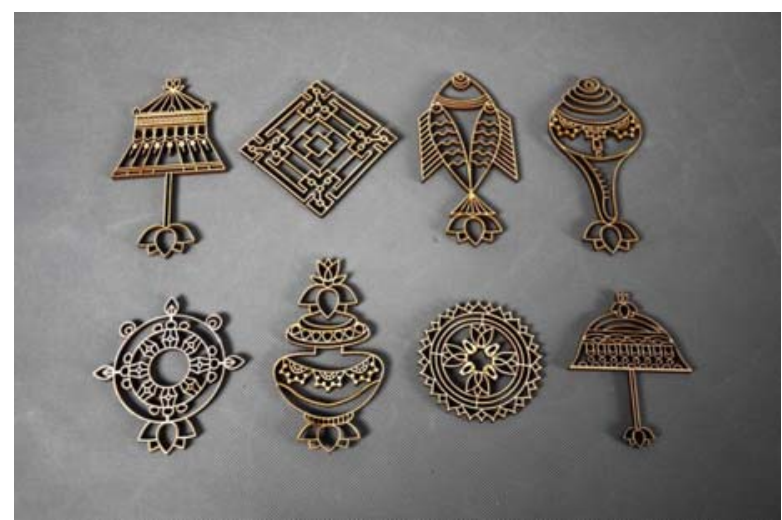

Figure 4 The purple gold and eight auspicious handmade gifts

Jiaoshan Buddhist Academy mainly cultivates research-oriented talents who are good at Buddhist calligraphy and painting and can meet the needs of the country and Buddhism. Combining with the cultivation of Buddhist painting and calligraphy art monks, the cartoon art image as shown in Figure 5 is more easily accepted by young people. The cartoon image has three basic images, with various styles and forms, and strong character characteristics. The first basic image is short and lovely, the second is fat, honest and honest; the third is tall and elegant.

The three monks are proficient in all aspects of Buddhism, calligraphy and painting. In order to promote it in the network, they have designed a number of cartoon expression bags and bookmarks of the Buddhist Academy (as shown in Figure 6). As a carrier of Buddhist culture and a Bridge for communication with young people, the creativity of Buddhism Department cultural creative products in Buddhist Academy needs to play its cultural self-confidence and the value of spreading traditional culture.

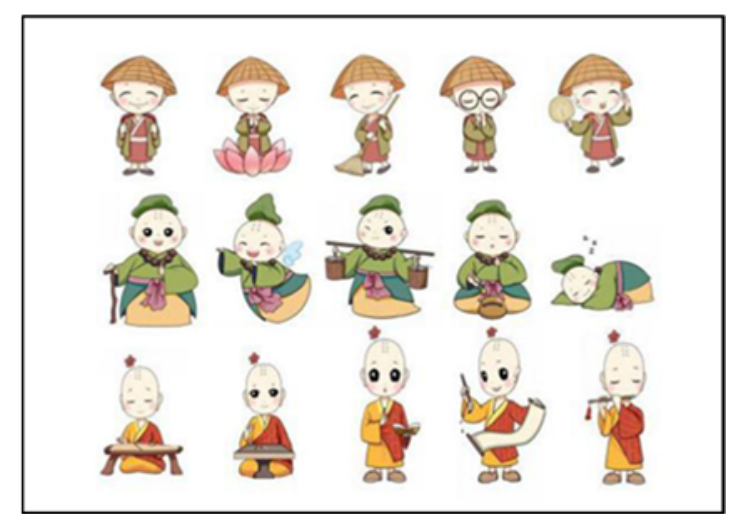

Figure 5 cartoon art image of Monks

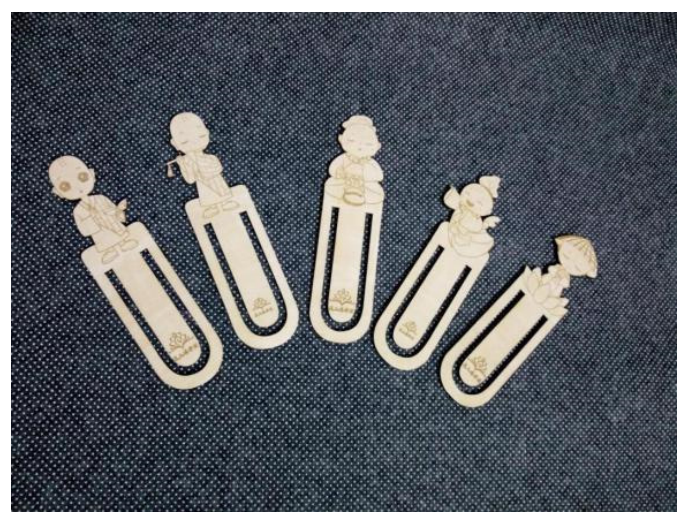

Figure 6 Bookmark

\section{Conclusion}

The design scheme of the logo of Jiaoshan Buddhist Academy is round and mellow, concise and generous, and highly generalized, with profound implication. In terms of visual effect, it has a strong sense of care, tenderness and ethereal. It has the visual recognition of Buddhism and Learning and can produce the Artistic Association of the growth of all things. The color design is mainly based on the purple Buddha color design. The whole figure points to the Buddhist monk (sitting Buddha) in Lotus. The Buddhist practice of symbolism monk (believer) can achieve the ultimate state of great fullness. Lotus and Buddhism blend into an integration. The lotus pattern is applied to the logo design of Buddhist Academy and the extension of brand visual design and cultural and creative product design. After integrated with Chinese traditional Buddhist culture and art, it forms a cultural symbol with unique Buddhist art style and innovative transmission of Buddhist. The application of patterns in the logo design of Buddhist Academy will make the logo design of Buddhist College obtain more abundant Buddhist cultural connotation and expression forms and make lotus pattern more innovative in logo design.

\section{FOUNDATION}

Research achievements of general projects of Philosophy and Social Sciences in Jiangsu Province

This is a general project of Philosophy and Social Sciences in Jiangsu Province named Research on the inheritance and brand effect of regional Buddhist Culture -- Taking Jiaoshan Buddhist Academy in Zhenjiang for instance with project no.: 2019sja1878.

\section{REFERENCES}

1. Xing Zhong, China Buddhist College: cultivating high-quality talents with patriotism and love of teaching [J]. Chinese religion, 2019 (05): 16-19.

2. Zhiqiang Zhou, Jiudong Zhang, Dinghuijizhao HuaYanJi, Jiaoshan Dinghui temple, Zhenjiang City, Jiangsu Province [J]. Chinese religion, 2018 (04): 76-77 
3. Lili Fan, Lotus image in Buddhism [J]. Literary (theoretical Edition), 2010 (06): 211-212

4. Hongmei Li, Analysis of the design of Buddhist visual recognition system $[\mathrm{J}]$. Popular literature and art, 2011 (15): 65-66

5. Xincheng, Hesheng, Shuming, Four masters, a generation of eminent monks [n]. China Nationalities daily, July 5, 2011 (007)

6. Siyu Hua, Research on the design of teaching cultural and creative products taking Jiaoshan Buddhist Academy in Zhenjiang[J]. Tiangong, 2019 (12): 140-141 